\section{Sarcocystosis in Mithuns Bos frontalis - a report}

\section{Swapna Susan Abraham ${ }^{1}$, C.S. Jayakumar ${ }^{2} \&$ Jacob Alexander $^{3}$}

${ }^{1}$ Veterinary Surgeon, Chief Disease Investigation Office, Pacha, Palode, Thiruvananthapuram, Kerala, India

${ }^{2}$ Veterinary Surgeon, Zoo, Thiruvananthapuram, Kerala, India.

${ }^{3}$ Veterinary Surgeon, District Clinical Laboratory,

Thiruvananthapuram, Kerala, India

Email: ${ }^{1}$ swapnasusan2003@yahoo.co.in

Sarcocystis infection is encountered normally during histological examination and so a diagnosis is usually made after the animal's death. In most animals sarcocystis infections are not considered to be of any pathogenic significance. However, heavy infections have caused mortality. In heavy infections, lameness, weakness and paralysis have been reported.

Sarcocystis is worldwide in distribution. It is found in many species including sheep, cattle, horse, swine, dogs, cats, rabbits, mice, chicken and humans. Many wildlife species have been found to be infected. However, reports in Mithuns (Bos frontalis) are limited. Hence, this case is documented to place on record the incidence in this species of animal.

Representative tissue samples collected from Mithuns, from a herd of seven animals at the Zoological Park, Thiruvananthapuram, Kerala for routine histopathological examination forms the basis of this report. The herd was severely affected with Foot and Mouth Disease with heavy mortality. Tissue sample sections were processed with hematoxylin-eosin stain.

Microscopic examination of heart revealed presence of numerous sarcocysts (1-2/HPF) in the cardiac muscle (Image 1). Focal areas of hemorrhage, congestion, edema and accumulation of fibrin between the cardiac muscle fibers was also observed. There was also focal infiltration with inflammatory cells and fragmentation of cardiac muscle.

In the present case sarcocysts in large numbers were observed in three Mithuns out of five samples of the same herd. Although no significant pathogenicity has been reported, heavy infections have caused mortality and clinical signs like intermittent pyrexia, loss of condition, abortion etc in cattle (Soulsby 1982). Sarcocystis associated with marked inflammatory response and rupture of cardiac muscles was reported earlier

Date of publication 26 April 2009

ISSN $0974-7907$ (online) | 0974-7893 (print)

Editor: Jacob V. Cheeran

Manuscript details:

Ms \# 01907

Received 13 December 2007

Finally accepted 12 December 2008

Citation: Abraham, S.S., C.S. Jayakumar \& J. Alexander (2009). Sarcocystosis in Mithuns Bos frontalis - a report. Journal of Threatened Taxa 1(4): 252.

Copyright: (C) Swapna Susan Abraham, C.S. Jayakumar \& Jacob Alexander 2009. Creative Commons Attribution 3.0 Unported License. JoTT allows unrestricted use of this article in any medium for non-profit purposes, reproduction and distribution by providing adequate credit to the authors and the source of publication.
(Bineesh et al. 2006). However, in the present case the other cardiac lesions observed could not be correlated to the presence of sarcocysts with certainty as the herd was severely affected with FMD with causalities due to complications. Sarcocyts in Mithuns have been recorded in Nandankanan Biological Park, Orrisa. However, the prevalence in this species is unknown.

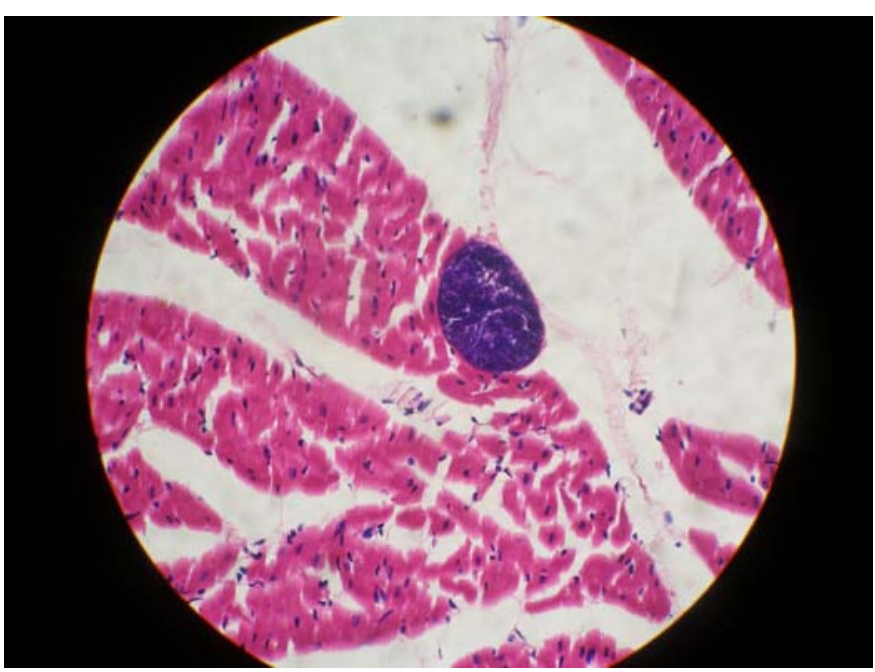

Image 1. Sarcocyst in the heart muscle. H \& E, x400

Apparently the disease is recorded in this species in our country and necessitates detailed studies on the various facets of host parasite relationship.

\section{References}

Soulsby, E.J.L. (1982). Helminths, Arthropods and Protozoa of Domestic Animals. $7^{\text {th }}$ edition. ELBS Publications, Tindall.

Bineesh, P.P., S. Sharma, S.K. Kansal, H.S. Banga \& R.S. Brar (2006). Sarcocystosis in a chicken. The Indian Veterinary Journal 83: 809 